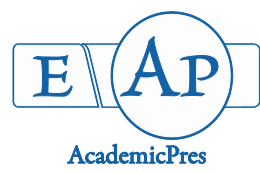

\title{
Development of Male and Female Gametophyte in Symphytum orientale L. (Boraginaceae)
}

\author{
Filiz VARDAR*, Ertuğrul Ali YAVUZ \\ Marmara University, Science and Arts Faculty, Department of Biology, Göztepe, 34722, Istanbul, \\ Turkey; filiz.vardar@gmail.com (*correspondingauthor); ertugrulyavuz90@hotmail.com
}

\begin{abstract}
The presented study elucidates developmental features of male and female gametophyte in Symphytum orientale L. (Boraginaceae). Flower buds were collected from natural habitats (İstanbul-Turkey) in March-April. The anthers of $S$. orientale were tetrasporangiate with a persistent epidermis and its wall development conformed to the Dicotyledonous type. The endothecium developed fibrous wall thickenings. The middle layer was short-lived and the cells of the glandular tapetum became double nucleated. In the microspore mother cells cytokinesis originated simultaneously after meiosis and the microspore tetrads were tetrahedral or isobilateral. The mature pollen grains were 3-celled when spread to environment. The ovule was hemianatropous, unitegmic and tenuinucellar. The megaspore mother cell functioned directly from the archesporial cell. Polygonum type embryo sac developed from the chalazal megaspore of a linear tetrad generated after meiosis. The synergids were pyriform and the polar nuclei fused shortly before fertilization. The antipodal cells were large and persistent at the stage of globular embryo. Embryogenesis followed the Chenopodiad type and the endosperm represented cellular type. The detailed embryological data of Symphytum orientale L. (Boraginaceae), which is a herbaceous and perennial flowering plant will improve our knowledge of its reproductive behaviour, and provide to comprehend taxonomic connection with related taxa within the Symphytum/Boraginaceae.
\end{abstract}

Keywords: anther, embryo, ovule, pollen, polygonum.

\section{Introduction}

The Boraginaceae family has 1600 species distributed among 110 genera (Cohen, 2013) including Symphytum which is a mesophytic genus with approximately 40 species, with a center of origin in the Pontic province of the EuroSiberian region. Turkey reserves the largest number with 18 Symphytum species (Tarıkahya-Hacioglu and Erik, 2011). They predominantly grow in meadows which has a moist and fertile soil mainly. They can also be grown up in damp habitats such as river sides. Some Symphytum species and hybrids are used in gardening (forage plant) and herbal medicine (Zarzycki et al., 2002). Its species are known by the common name comfrey. Symphytum orientale (eastern comfrey) is a herbaceous and perennial flowering plant as well as the other members of Symphytum genus.

Although various studies have been performed on Symphytum genus in recent years, most of them are pointed to their chemical structure, karyology and phylogenetic analysis including morphological and molecular characters (Ulubelen and Doğanca, 1971; Ahmad et al., 1993;
Mohammed et al., 1995; Akçin and Baki, 2009; Cohen, 2013). The best of our knowledge, there is little available information on the embryologic characters of Symphytum.

The reproductive information of plants provides effective data for cell biology, ecology of reproduction, and systematic taxonomy, likewise being invaluable for objectives related to efficient seed production, crossbreeding and hybridization. Although inflorescence, flower color, style type, anther wall development, ovule type, sporogenesis, gametogenesis and pollen morphology have received the most attention for characters of taxonomic importance in the angiosperms, other ovular features such as the number of integuments, position of megaspore mother cell in the nucellus, presence or absence of endothelium, aril, obturator, hypostase and nucellar cap are essential for their ability to display taxonomic distinction (Stuessy, 2009; Tekşen and Aytaç, 2011).

In addition, the developmental characters of anther, ovule and embryo appear to be very important not only for taxonomic connection, but also for the understanding of development, pollination and fertilization behavior. Ovule development of $S$. orientale were carried out simply by Pitot 
(1937) and to the best of our knowledge there is no previous detailed information available on the development of anther, ovule and embryo as well as the other members of Symphytum genus. This research represents the first detailed observations about the male-female gametophyte development of $S$. orientale (Boraginaceae). This study will obtain a detailed knowledge of the events that leads to pollen and embryo development. Knowledge on the development of the male and female reproductive structures in S. orientale L. will also improve our perception of its reproductive behavior, and provide to improve taxonomic connection with related taxa in the Boraginaceae.

\section{Materials and Methods}

Flower buds of Symphytum orientale L. (Boraginaceae) were collected in March-April 2013 in the environs of Göztepe-İstanbul (Turkey). Different sized buds were fixed in glacial acetic acid and absolute alcohol in proportion as $1: 3(\mathrm{v} / \mathrm{v})$ overnight. Fixed material was dehydrated in a graded alcohol series and embedded in paraffin. Longitudinal paraffin sections $(8-10 \mu \mathrm{m})$ were cut using a Leica RM2125RT microtome, deparaffinized in alcoholxylol series and stained with Delafield's hematoxylin. The stained sections monitored and photographed with Kameram software, supported with a Kameram camera and an Olympus BX-51 microscope.

\section{Results}

\section{Male gametophyte development}

The androecium in Symphytum orientale L. consisted of 5 stamens which adnated to the corolla from their filaments (epipetalous). The protandrous anther was able to move (versatile) and tied to the filament on the outward facing surface (dorsifixed) (Fig. 1a). The anther dehisced with longitudinal slits at maturity (Fig. 1b). After anther dehiscence stamens fell off together with the corolla.

The undifferentiated anthers of $S$. orientale were oval in shape and comprised meristematic cells surrounded by epidermis. The anther formed to tetrasporangiate concurrent with development. In the anther lobes archesporial cells were differentiated from the hypodermal cells. These cells organized into a parallel plane to the outer wall of the anther with periclinal divisions. The concentric parietal layer cells formed endothecial, middle and tapetal layer (dicotyledonous type) by a series of periclinal and anticlinal divisions. Simultaneously the enlarged sporogenous cells underwent mitotic divisions before generating pollen mother cells (PMCs). The expansion of pollen sacs was ongoing during meiotic division of PMCs. Subsequent to the pollen maturation these sacs combined by tissue fusion. Concurrent with longitudinal dehiscence of stomium the mature pollen grains scattered to the environment (Fig. 1b).

In $S$. orientale an anther locule including the developing microspores was bounded by tapetal layer, middle layer, endothecial layer and epidermal layer at the early developmental stages. The PMCs and secretory tapetal cells were appeared same with their distinctive nuclei and large volume (Fig. 1c). At the beginning of meiosis in the PMCs, tapetal cells underwent mitotic divisions. At the end of mitosis, no cell plate was formed; therefore, 2 diploid nuclei persisted inside the tapetal cell (Fig. 1d). At tetrad stage, tapetal cells enlarged maximum, its cytoplasm became denser and the middle layer started to degenerate (Fig. 1e). After callose dissolution the tapetum started to undergo significant alterations in cell structure, including nuclear deterioration characterized by loss of spherical shape, and nuclear deformation. Meanwhile initiation of endothecial wall thickenings was observed (Fig. 1f). Although the middle layer and the tapetal layer degenerated entirely at pollen maturation stage, epidermis and U-shaped endothecium remained in the mature anther wall bordering mature pollen grains (Fig. 1g).

In the PMCs of $S$. orientale the processes of meiotic division and pollen development proceeded regularly within all anthers of the same flower. Simultaneous cytokinesis was occurred after meiotic division. Callose started to accumulate in the corners of PMCs in the beginning of prophase I. Microspore tetrads mostly arranged in tetrahedral or isobilateral, and a callose wall separated the four microspores from each other (Fig. 2a, b). After callose dissolution the spherical free microspores had centered nucleus with one or two nucleoli (Fig. 2c). After vacuole
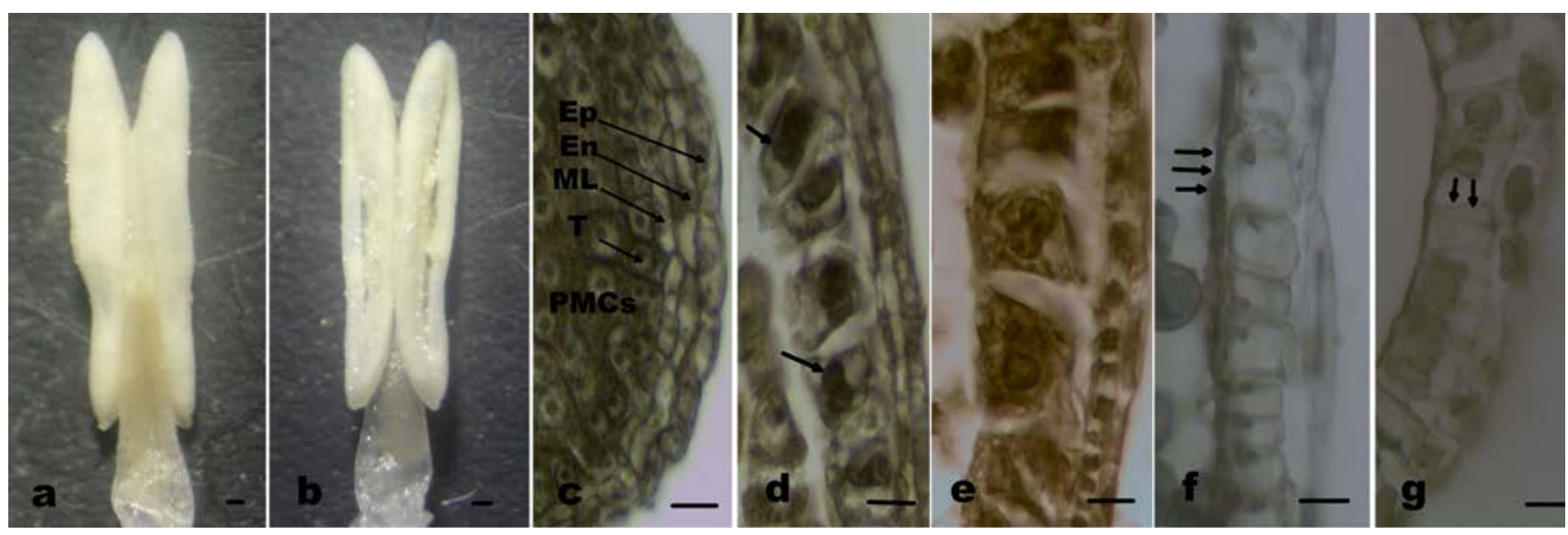

Fig. 1. Anther and anther wall cells of S. orientale. a. The versatile anther which is tied to the filament on the outward facing surface (dorsifixed). b. The longitudinal anther dehiscence. c. Premeiotic stage. d. Binucleated cells (arrows) in the tapetum at the beginning of meiosis of the PMCs. e. Enlarged tapetal cells and degenerated middle layer at tetrad stage. (f) Tapetal degeneration after callose dissolution (arrows). g. Endothecial wall thickenings (arrows) at mature pollen stage. PMCs: Pollen mother cells, Ep: epidermis, En: endothecium, ML: middle layer, T: tapetum (Bar: $10 \mu \mathrm{m})$ 
126

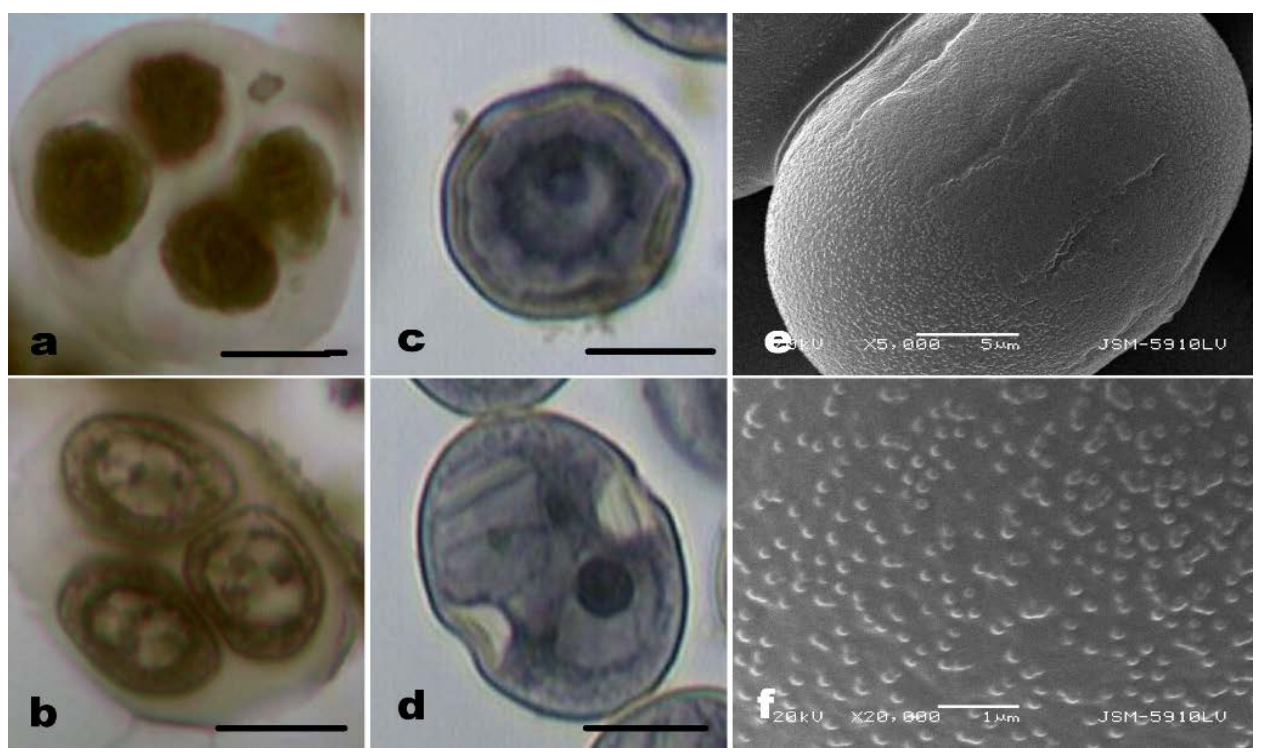

Fig. 2. Isobilateral (a) and tetrahedral (b) microspore tetrads of S. orientale. Young (c) and mature (d) pollen grains. (e, f) SEM micrographs of mature pollen (Bar: $10 \mu \mathrm{m})$

expansion the microspore increased in volume, and the nucleus displaced to peripheral cytoplasm (Fig. 2d). Pollen mitosis occurred in the vacuolated stage, and originated in a large vegetative and a small generative cell. At anther dehiscence time the pollen grains were 3-celled with two sperm cells and a vegetative cell with a spherical nucleus and a nucleolus. The elliptical sperm cells elongated afterwards. The morphological characteristics of mature pollen were 6zonocolporate, prolate and isopolar. The pollen grain had granulated type of exine structure (Fig. 2e, f).

\section{Female gametophyte development}

The superior ovary of $S$. orientale displayed a secondary (false) septum, producing 4 loculi and each of these had only a single ovule (Fig. 3a). The gynobasic and hollowed style extended out of the corolla and had papillated stigma (Fig. 3b-d). At the end of the style and at the base of the placenta, obturator (placental obturator) was visible which are responsible for directing the pollen tubes to the micropyle of the ovules. The obturator cells consisted thick-walled, columnar and glandular cells (Fig. 3e).

The mature ovule was hemianatropous, unitegmic (Fig. 3f) and tenuinucellate (Fig. 4a). The integument initiated as a small protuberance first, and throughout the development the integument became multilayered. Thus the micropylar aperture became as a narrow and long tube. The nucellar epidermis was composed of multilayered cuboidal cells.

Megasporogenesis was initiated by the development of a hypodermal archesporium cell which had a large volume, dense cytoplasm and apparent nucleolus (Fig. 4a). Development progressed with mitosis of the archesporium cell, originating a parietal cell and a primary sporogenous cell. The primary sporogenous cell enlarged to form megaspore mother cell (MMC) and underwent meiosis forming linear megaspore tetrad. The unique functional megaspore was always the larger chalazal member

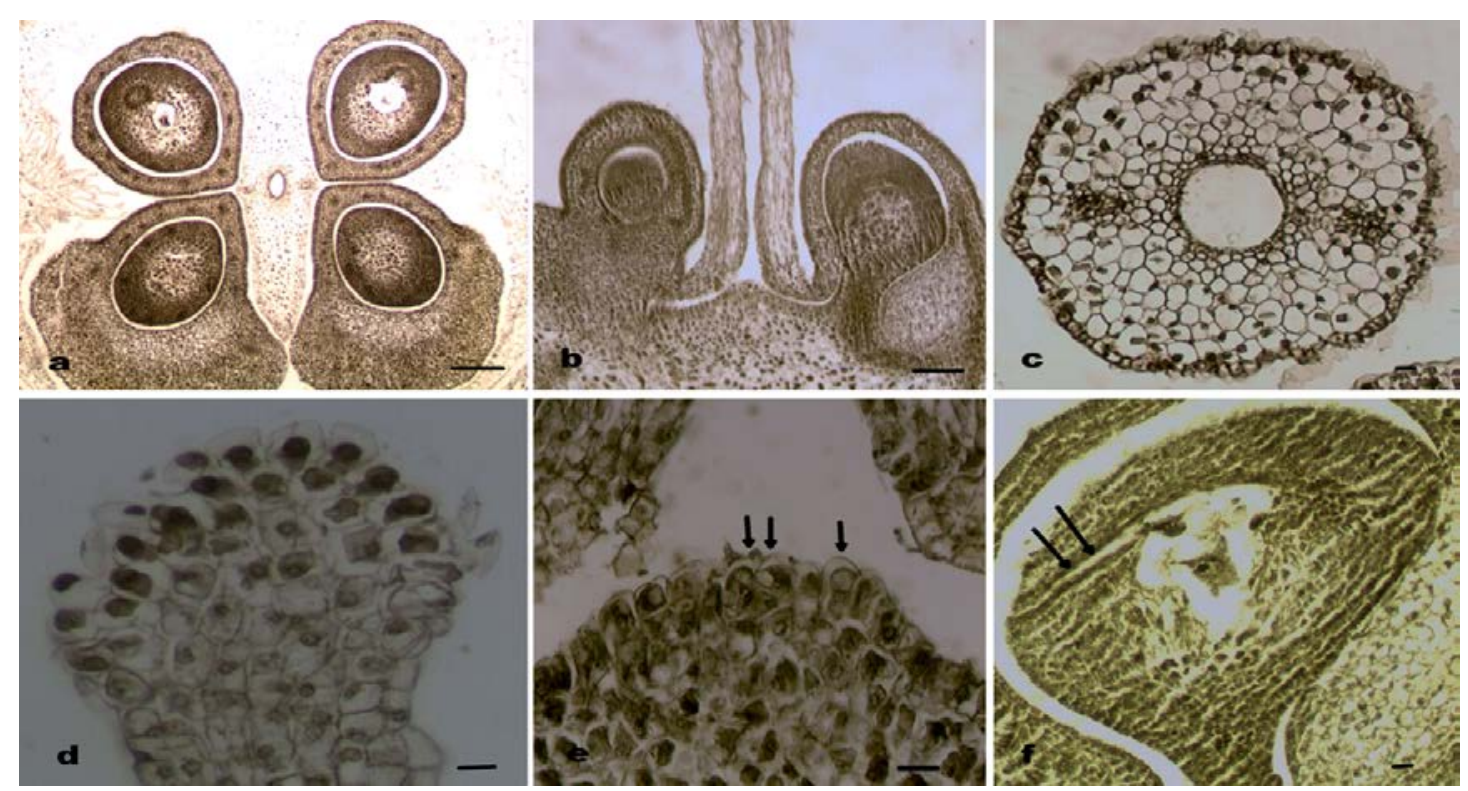

Fig. 3. Ovular structures of S. orientale. a. Cross section of the ovary. b, c. Gynobasic and hollowed style. d. Papillated stigma. e. Papillae cells (arrows) at the base of the placenta. f. Position of micropyle (arrows) (Bar: $10 \mu \mathrm{m})$ 

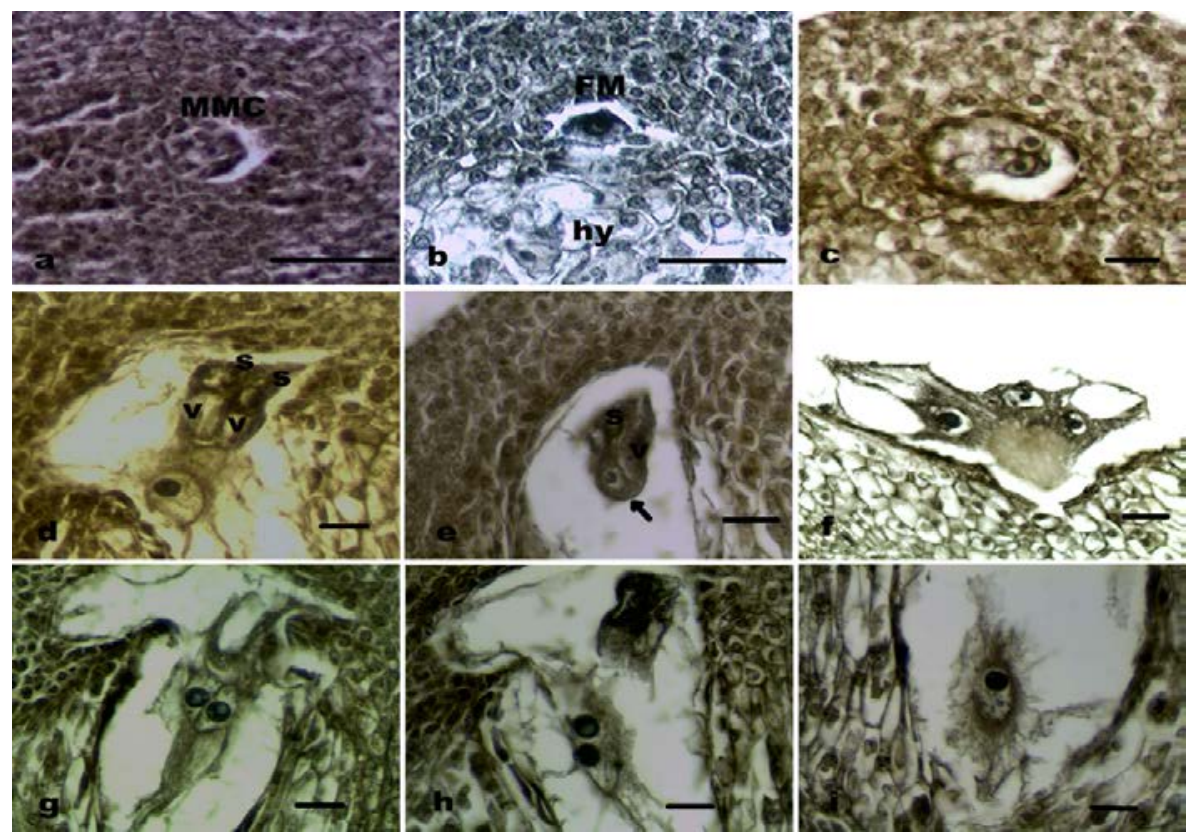

Fig. 4. Development of embryo sac (ES) in S. orientale. a. Megaspore mother cell (MMC). b. Functional megaspore (FM) at chalaza. c. 4-nucleate ES (two of the nuclei are observed). d. Two synergids (s). e. Fertilized egg (arrow) and degenerated synergid. f. Antipodals. g. Two polar nuclei. h. Fusion of polar nuclei. i. Secondary nucleus. hy: hypostase, v: vacuole (Bar in a, b: $100 \mu \mathrm{m}$; in c-i: $10 \mu \mathrm{m})$

(monosporic embryo sac). The ovule constituted hemianatropous type at the functional megaspore (FM) stage. The nucellar cells below the embryo sac differentiated into a hypostase as the ovule development. The first hypostase cells were visible at the FM stage (Fig. 4b). The number of cells increased in further stages and became more prominent in the mature embryo sac. The wide hypostase cells of mature embryo sac were thin walled, each containing poor cytoplasm and large vacuole.
The FM increased in diameter, extended into the micropylar region and developed into the embryo sac (ES). After mitotic divisions the FM became 2, 4 and 8-nucleate ES leading to a Polygonum type (Fig. 4c). Three micropylar nuclei developed into an egg apparatus including an egg and two pear-shaped synergids lying above the egg. After fertilization, synergids degenerated simultaneously (Fig. 4d, e). The three chalazal nuclei formed antipodals locating in the periphery at the chalazal side of the ES. The antipodals

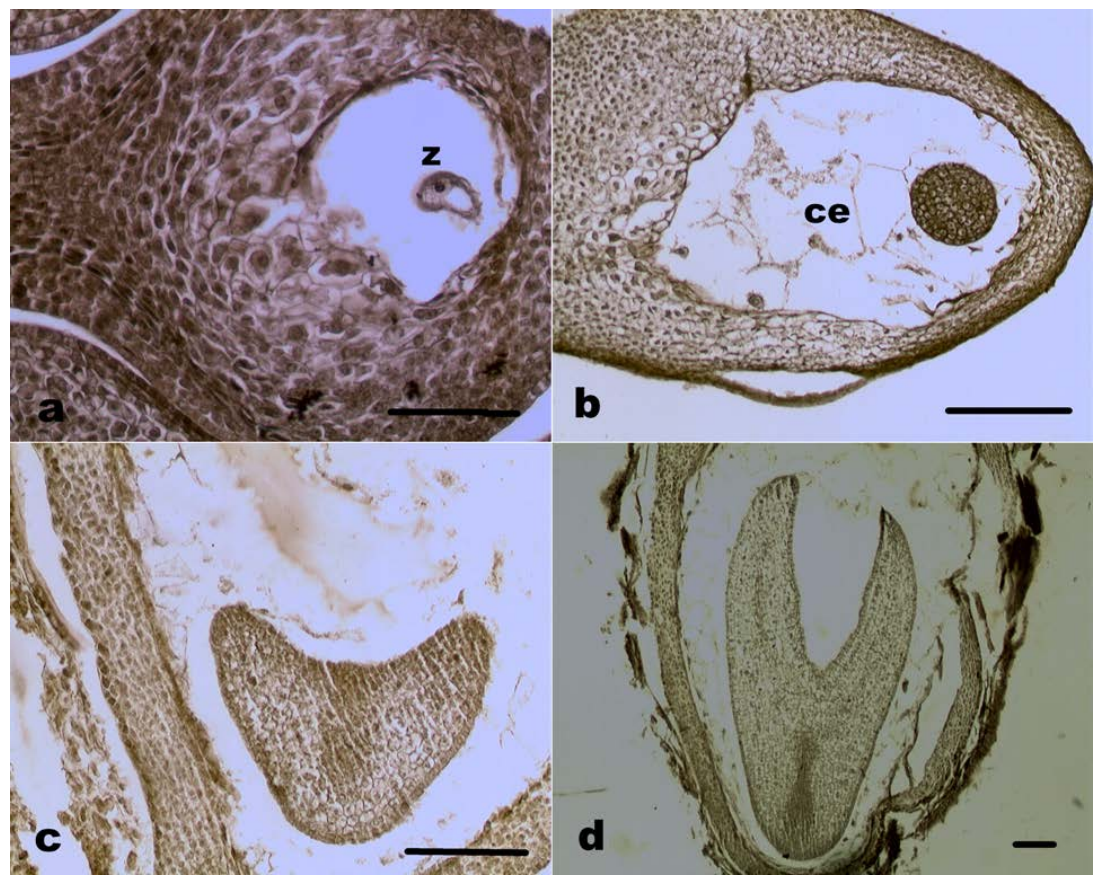

Fig. 5. Development of embryo in S. orientale. a. Zygote (z). b. Globular embryo and cellular endosperm (ce). c. Heart stage. d. Torpedo stage (Bar in a: $10 \mu \mathrm{m}$; in b-d: $100 \mu \mathrm{m}$ ) 
128

were persistent and started to degenerate at the globular embryo stage (Fig. 4f). The remained fourth nuclei at the micropyl and chalaza located at the center of ES and constituted the polar nuclei (Fig. 4g). The polar nuclei fused to generate a secondary nucleus shortly before fertilization, and located by the near side of the egg (Fig. 4h, i). After double fertilization the secondary nucleus originated the primary endosperm nucleus.

\section{Embryo and endosperm development}

Chenopodiad type embryo development was identified in S. orientale. Zygote existed at the micropylar region of the ES. As a consequence of vacuolar reduction the zygote was smaller than the egg (Fig. 5a). The first division of zygote was transverse generating an apical (ca) and a basal cell (cb) almost equal sized. Subsequently, the ca divided transversely. A vertical wall divided the two daughter cells of ca comprising a proembryo consisting of four cells. Subsequent divisions gave rise to a globular embryo. The cb divided also transversely producing two superimposed cells. The cb constituted the suspensor, which became larger concurrent with development. The suspensor persisted until globular embryo and then degenerated (Fig. 4b). The embryo was at torpedo stage when the seeds were ready for dispersal (Fig. $4 \mathrm{c}, \mathrm{d}$ ). The primary endosperm nucleus underwent mitotic divisions prior to divisions in the zygote. S. orientale represented cellular endosperm in which cell-wall formation was coincident with nuclear divisions.

\section{Discussion}

Although Boraginaceae is one of the most familiar families, and analyzed by the aspects of taxonomic characters, fruit coat patterns (Akçin and Baki, 2009), flower ecology (Denisow, 2008), pollen-pistil interaction (Ghorbel and Nabli, 1998) and pollen cytology (Montaner et al., 2003), related embryological data are limited. It has been known that studies on sexual process and reproduction are supplementary to phylogenetics and of special value at the genus level (Grant, 1981). Similarly, Taylor and Osborn (2006) stated that to reveal the different features of anther and ovule structure and development is useful for assessing phylogenetic relationships.

The development of male gametophyte was not considered in Symphytum, except exine substructure of Symphytum officinale (Gabarayeva et al., 2011). The development of anther wall in Boraginaceae was indicated as Dicotyledonous type (Davis, 1966), consisting Cordia sebestena (Khaleel, 1982), Heliotropium scabrum and $H$. strigosum (Khaleel, 1978). Our results confirmed that anther development of $S$. orientale also belonged to Dicotyledonous type. Overall the reported results represented that certain characters such as protandrous and tetrasporangiate anther, glandular and multinucleated tapetum, tetrahedral and isobilateral microspore tetrads and 3 -celled pollen are common in the family of Boraginaceae (Davis, 1966; Khaleel, 1978; Khaleel, 1982; Rao and Rao, 1992; Gabarayeva et al., 2011). According to our results structural and developmental features of anthers in $S$. orientale are compatible with the family.
Although Boraginaceae is a widespread family, embryological features has attracted little attention as it was in Symphytum. The best of our knowledge, the unique report containing the ovule development of $S$. orientale was performed by Pitot (1937). The report was lack of the detailed identification of the position of megaspore mother cell, ovule, integument, embryo sac, embryo and endosperm type. Ovule shape, ovule type, number of integuments, micropyle formation constitutes ovule characteristics and are important for the phylogenetic analysis in particular. $S$. orientale has hemianatropous, unitegmic and teuniunucellate ovule consistent with Boraginaceae family (Davis, 1966). Rao and Rao (1992) described the development and structure of ovule, megasporogenesis and megagametogenesis of 9 species of 7 genera belonging to Boraginaceae. The researchers indicated that the common features were unitegmic, tenuiunucellate and hemianatropous ovule and Polygonum type embryo sac. Besides these characters Berg (2009) mentioned that Neomphila species showed Chenopodiad type embryogenesis and cellular endosperm as it was in $S$. orientale. However, Khaleel (1978) reported Onagrad type embryogenesis in Heliotropium scabrum and H. strigosum distinctively.

\section{Conclusions}

The present paper is the first detailed research on anther and ovule development in Symphytum orientale, as well as in the genus Symphytum. The detailed embryological data of Symphytum orientale L. (Boraginaceae), which is a herbaceous and perennial flowering plant will help improve our understanding of its reproductive behaviour and seed formation, and provide to understand its taxonomic relationship with closely related taxa within the Symphytum/Boraginaceae.

\section{Acknowledgements}

We thank to Professor Dr. Meral Ünal for her valuable comments and discussions about our data.

\section{References}

Ahmad VU, Noorwala M, Mohammad FV, Sener B, Gilan AH, Aftab K (1993). Symphytoxide A, a triterpenoid saponin from the roots of Symphytum officinale. Phytochemistry 32:1003-1006.

Akçin ÖE, Baki H (2009). Fruit coat patterns and morphological properties of seven species of Symphytum L. (Boraginaceae) from Turkey. Bangladesh Journal of Botany 38:185-188.

Berg RY (2009). Embryo sac, endosperm, and seed of Nemophila (Boraginaceae) relative to taxonomy, with a remark on embryogeny in Pholistoma. American Journal of Botany 96:656-579.

Cohen JI (2013). A phylogenetic analysis of morphological and molecular characters of Boraginaceae: Evolutionary relationships, taxonomy, and patterns of character evolution. Cladistics 29:1-31.

Davis OL (1966). Systematic Embryology of the Angiosperms. John Wiley and Sons, NewYork. 
Denisow B (2008). Flowers ecology and pollen output of Symphytum officinale L. Journal of Apicultural Science 52:81-89.

Gabarayeva N, Grigorjeva V, Polevova S (2011). Exine and tapetum development in Symphytum officinale (Boraginaceae). Exine substructure and its interpretation. Plant Systematics and Evolution 296:101-120.

Ghorbel S, Nabli MA (1998). Pollen, pistil and their interrelations in Borago officinalis and Heliotropum europaeum (Boraginaceae). Grana 37:2032014.

Grant V(1981). Plant speciation. Columbia University Press, New York.

Khaleel TF (1978). Embryology of Heliotropium scabrum and H. strigosum (Boraginaceae). Plant Systematics and Evolution 129:45-62.

Khaleel TF (1982) Embryology of Cordia sebestena (Boraginaceae). Plant Systematics and Evolution 139:303-311.

MohammedFV, Norwala M, AhmadVU, Şener B (1995). A bidesmosidic hederagenin hexasaccharide from the roots of Symphytum officinale. Phytochemistry 40:213-218.

Montaner C, Floris E, Alvarez JM (2003). Study of pollen cytology and evaluation of pollen viability using in vivo and in vitro test, in borago (Borago officinalisL.). Grana 42:33-37.

Pitot A (1937). Le development de l'ovule chez le Symphytum orientale L [Ovule development of Symphytum orientale L.]. Bulletin de la Societe Botanique de France 84:149-153.
Rao BH, Rao PSP (1992). Sporogenesis and gametogenesis of some Boraginaceae. Feddes Repertorium 103:35-40.

Stuessy TF (2009). Plant taxonomy: The systematic evaluation of comparative data. Columbia University Press, New York.

Tarkkahya-Hacioğlu B, Erik S (2011). Phylogeny of Symphytum L. (Boraginaceae) with special emphasis on Turkish species. African Journal of Biotechnology 10:15483-15493.

Taylor ML, Osborn JM (2006). Pollen ontogeny in Brasenia (Cabombaceae, Nymphaeales). American Journal of Botany 93:344 356.

Tekşen M, Aytac Z (2011). The revision of the genus Fitillaria L. (Liliaceae) in the Mediterranean region (Turkey). Turkish Journal of Botany 35:447 478 .

Ulubelen A, Doğanca S (1971). Alkaloidal and other constituents of Symphytum orientale. Phytochemistry 10:441-442.

Zarzycki K, Trzcińska-Tacik H, Różański W, Szelag W, Wołek Z, Korzeniak U (2002). Ecological indicator values of vascular plants of Poland. Szafer Institute of Botany, Polish Academy of Science, Krakow, Poland. 